\title{
Interleukin-6 Trans-signaling: A Pathway With Therapeutic Potential for Diabetic Retinopathy
}

\author{
Shruti Sharma ${ }^{1,2,3 *}$ \\ ${ }^{1}$ Center for Biotechnology \& Genomic Medicine, Medical College of Georgia, Augusta University, Augusta, GA, \\ United States, ${ }^{2}$ Department of Ophthalmology, Medical College of Georgia, Augusta University, Augusta, GA, United States, \\ ${ }^{3}$ Culver Vision Discovery Institute, Medical College of Georgia, Augusta University, Augusta, GA, United States
}

Keywords: interleukin-6, IL-6 trans-signaling, sgp130Fc, inflammation, diabetic retinopathy

\section{NEW THERAPIES FOR DIABETIC RETINOPATHY ARE AN URGENT UNMET NEED}

Diabetic retinopathy (DR), a sight-threatening neurovasculopathy, is the leading cause of blindness in working-aged adults (Zhang et al., 2010; Hendrick et al., 2015). DR is characterized by pathologic vascular proliferation, oxidative damage, and inflammation within the retina (Tang and Kern, 2011; Antonetti et al., 2012; Klaassen et al., 2013). The progression of DR is highly correlated to the duration of diabetes (Fong et al., 2004). While restoring glycemic control and regulating other systemic factors are important for slowing DR development, limited therapeutic options are available once symptoms progress, and these are primarily aimed at treating late-stage disease (Fullerton et al., 2014; Do et al., 2015; Lee et al., 2015; Gardner and Sundstrom, 2017).

The number of DR patients is expected to increase over the coming decades. Currently, the

OPEN ACCESS

Edited and reviewed by: George E. Billman, The Ohio State University, United States

*Correspondence: Shruti Sharma

shsharma@augusta.edu

Specialty section:

This article was submitted to

Redox Physiology

a section of the journal

Frontiers in Physiology

Received: 31 March 2021 Accepted: 12 April 2021

Published: 19 May 2021

Citation:

Sharma S (2021) Interleukin-6 Trans-signaling: A Pathway With Therapeutic Potential for Diabetic

Retinopathy.

Front. Physiol. 12:689429 doi: 10.3389/fphys.2021.689429 only recommended treatments for advanced retinopathy are laser photocoagulation or anti-VEGF injections, but a substantial proportion of patients are resistant to these treatments. Laser photocoagulation can control pathological neovascularization, but it may lead to complications, such as impaired central vision, nocturnal diminution of vision, and blindness. The beneficial effects of anti-VEGF injections are usually transient, as the treatment does not promote tissue repair, and repeated injections increase the risk of intraocular infection. Furthermore, despite receiving anti-VEGF injections, a small proportion of patients with macular edema still show persistent disease (Lavine et al., 2017; Roy et al., 2017). Moreover, neither treatment targets early-stage disease. Another study examined the effect of candesartan, an angiotensin-II receptor antagonist, on patients with type 1 diabetes and found a moderate $18 \%$ reduction in incidence of retinopathy with no effect on the progression of existing retinopathy (Group and Chaturvedi, 2002). Therefore, new therapies to prevent retinal injury and enhance repair represent a critical unmet need.

\section{INTERLEUKIN-6 TRANS-SIGNALING: A POTENTIAL THERAPEUTIC TARGET FOR DIABETIC RETINOPATHY}

The pleiotropic cytokine, interleukin-6 (IL-6), is one of the major mediators of retinal vascular inflammation associated with DR (Shimizu et al., 2002; Funatsu et al., 2005; Mocan et al., 2006; Kawashima et al., 2007; Hou et al., 2008; Barnes et al., 2011; KolevaGeorgieva et al., 2011; Gustavsson et al., 2013; Koskela et al., 2013; Chen et al., 2016; Srividya et al., 2018; Valle et al., 2019). IL-6 signaling through its membrane-bound IL-6 receptor is known as "classical signaling." Importantly, IL-6 signaling is also observed in cells 
that do not express the membrane-bound IL-6 receptor through a soluble IL-6 receptor (sIL-6R), known as "trans-signaling" (Barnes et al., 2011; Rose-John, 2012). There is increasing evidence in the literature suggesting that IL-6 classical signaling is anti-inflammatory, whereas trans-signaling induces the proinflammatory effects of IL-6 (Rabe et al., 2008; Ebihara et al., 2011; Fisher et al., 2011; Scheller et al., 2011; Wei et al., 2013). Trans-signaling has also been reported to have stronger effects than classical signaling (Reeh et al., 2019).

Recent advances in the field have led to the development of several therapeutic interventions targeting IL-6 signaling pathways, including anti-IL6 antibodies: siltuximab, sirukumab, olokizumab, and clazakizumab; anti-IL6R antibodies: tocilizumab, sarilumab, satralizumab, and vobarilizumab; and selective inhibitors of IL- 6 trans-signaling only: sgp130Fc (olamkicept). Anti-IL6 and anti-IL6R therapeutic strategies globally block IL-6 signaling, essentially targeting both classical and trans-signaling pathways. Tocilizumab, an IL-6 receptorinhibiting monoclonal antibody, is useful in the treatment of various autoimmune and inflammatory conditions, notably rheumatoid arthritis (Ohsugi and Kishimoto, 2008). However, this treatment was associated with negative side effects, such as liver toxicity and increases in triacylglycerol and cholesterol levels (Kawashiri et al., 2011).

Long-term hyperglycemia-mediated oxidative stress and inflammation lead to blood-retinal barrier (BRB) dysfunction and increased vascular permeability, allowing extravasation of plasma proteins into the interstitium (Frey and Antonetti, 2011; Klaassen et al., 2013). This dysfunction leads to edema, deposition of hard exudates in the retina, microaneurysms, and retinal hemorrhage (Cheung et al., 2010; Cunha-Vaz et al., 2011; Eshaq et al., 2017). BRB breakdown and subsequent macular edema are the main causes of blindness in DR (Antonetti et al., 1999; Joussen et al., 2007; Gardner et al., 2009; Klaassen et al., 2013; Sugimoto et al., 2013; Kita et al., 2015; Lee et al., 2015). IL-6 plays a significant role in initiating BRB breakdown in DR (Mesquida et al., 2019; Valle et al., 2019). Studies have shown that IL-6 signaling decreases barrier function in retinal endothelial cells and increases vascular leakage through downregulating tight junction proteins (Yun et al., 2017; Jo et al., 2019). IL6 trans-signaling causes oxidative stress, inflammation, and endothelial barrier disruption in human retinal endothelial cells (Valle et al., 2019). Further, in a mouse model of early DR, inhibition of IL-6 trans-signaling significantly reduced diabetesinduced oxidative damage at the systemic level and in the retina (Robinson et al., 2020).

IL-6 also plays an important role in localized immune responses by mediating the recruitment of circulating leukocytes, attachment to the endothelium, and migration through the vascular wall (Romano et al., 1997; Rojas et al., 2010; Ebihara et al., 2011). Arrest and firm adhesion of leukocytes occur by their binding to endothelial cells using intercellular adhesion molecule 1 (ICAM-1) and vascular cell adhesion molecule 1 (VCAM1). In diabetic patients, increased ICAM-1 expression in retinal vessels is correlated with an increase in migrating neutrophils (Noda et al., 2012). We previously found elevated levels of soluble ICAM-1 and VCAM-1 in patients with DR (Sharma et al., 2015) and increased ICAM-1 protein levels in human retinal endothelial cells after IL- 6 trans-signaling activation (Valle et al., 2019). Numerous studies have demonstrated that IL-6 increases the expression of ICAM-1, VCAM-1, and selectins (Wung et al., 2005; Lin et al., 2013), but distinct roles of classical and trans-signaling have not been studied. Future studies delineating the relationship between IL- 6 trans-signaling and leukocyte migration in the retinal vasculature will enhance our understanding of inflammation and BRB breakdown associated with DR.

\section{MOLECULAR TOOLS FOR DELINEATING THE ROLES OF IL-6 CLASSICAL AND TRANS-SIGNALING}

\section{sgp130Fc}

The soluble gp130 (sgp130) is a natural inhibitor of IL-6 transsignaling (Wolf et al., 2016; Rose-John, 2017; Baran et al., 2018). The commercially available compound, sgp130Fc (soluble gp130Fc fused chimera), is an optimized fusion protein of the natural sgp130 and IgG1-Fc (Tenhumberg et al., 2008). sgp130Fc binds to IL-6 in complex with soluble IL-6R (IL-6/sIL-6R) and does not interfere with IL- 6 alone or IL- 6 bound to IL-6R on the cell surface. Therefore, sgp130Fc selectively inhibits IL-6 trans-signaling without disrupting IL-6 classical signaling via the membrane bound IL-6R. Compared to endogenous sgp130, sgp130Fc has been shown to possess 10 to 100 times greater ability for inhibiting IL-6 trans-signaling responses (Jostock et al., 2001). The use of this compound alongside existing global IL6 inhibitors allows for a direct comparison of the therapeutic potential of global vs. selective trans-signaling inhibition.

\section{Hyper IL-6}

Hyper-IL-6 is a fusion protein using a flexible peptide linker between soluble IL-6R and IL- 6 to connect both molecules. Therefore, instead of a mixture of IL-6 and soluble IL-6R, hyper IL- 6 can be used to stimulate IL- 6 trans-signaling in cells. Also, hyper IL- 6 is $\sim 100 \times$ more potent than the combination of IL-6/sIL-6R (Fischer et al., 1997; Jostock et al., 2001; Drucker et al., 2010). This compound is particularly useful for studies involving cells that express the membrane-bound IL-6 receptor, as a mixture of IL-6 and soluble IL-6R could theoretically activate both classical and trans-signaling. Hyper IL-6 allows for selective activation of IL- 6 trans-signaling without any classical signaling activation.

\section{L-gp130}

The transmission of the IL-6 signaling through the plasma membrane is mediated through glycoprotein $130 \mathrm{kDa}$ (gp130). IL-6 receptor associates with the ubiquitously expressed protein gp130, initiating dimerization and intracellular signaling. L-gp130 is a designer protein in which the entire extracellular portion of gp130 is replaced by the leucine zipper of the Jun protein for constitutive dimerization and activation. Thus, L-gp130 protein can be used for permanent gp130 activation to mimic constitutive IL-6 signaling in cells (Stuhlmann-Laeisz et al., 2006). 


\section{Transgenic Mice Overexpressing sgp130Fc}

Transgenic mice that constitutively overexpress sgp $130 \mathrm{Fc}$ are valuable resources to selectively block IL-6 trans-signaling in vivo (Rabe et al., 2008). Two types of transgenic mice are available for either central or peripheral expression of sgp130Fc. Peripheral sgp130Fc transgenic mice express sgp130Fc in the liver under the control of the phophoenol pyruvate-carboxykine (PEPCK) promotor for systemic release into the circulatory system (Rabe et al., 2008; Kraakman et al., 2015). The central sgp130Fc transgenic strain allows for inhibition of IL- 6 transsignaling in the central nervous system through sgp $130 \mathrm{Fc}$ expression under control of a glial fibrillary acidic protein (GFAP) promotor (Campbell et al., 2014). Functionally, these models mimic intravenous (peripheral) or intravitreal (central) drug delivery, two common methods used in the treatment of ocular diseases.

\section{CONCLUDING REMARKS}

Increasing evidence suggests that the IL-6 pathway plays a prominent role in the pathogenesis of DR. The complex IL6 receptor system allows for multiple signaling modalities, including classical signaling and trans-signaling. Classical signaling is critical for the regenerative or anti-inflammatory activities of IL-6, while recent studies have demonstrated that IL-6 trans-signaling is primarily pro-inflammatory. In DR, IL-6 trans-signaling mediates barrier disruption in retinal

\section{REFERENCES}

Antonetti, D. A., Klein, R., and Gardner, T. W. (2012). Diabetic retinopathy. N. Engl. J. Med. 366, 1227-1239. doi: 10.1056/NEJMra1005073

Antonetti, D. A., Lieth, E., Barber, A., and Gardner, T.W. (1999). "Molecular mechanisms of vascular permeability in diabetic retinopathy," in Seminars in Ophthalmology (Taylor and Francis), 240-248. doi: 10.3109/08820539909069543

Baran, P., Hansen, S., Waetzig, G. H., Akbarzadeh, M., Lamertz, L., Huber, H. J., et al. (2018). The balance of interleukin (IL)-6, IL-6.soluble IL-6 receptor (sIL-6R), and IL-6.sIL-6R.sgp130 complexes allows simultaneous classic and trans-signaling. J. Biol. Chem. 293, 6762-6775. doi: 10.1074/jbc.RA117.001163

Barnes, T. C., Anderson, M. E., and Moots, R. J. (2011). The many faces of interleukin-6: the role of IL-6 in inflammation, vasculopathy, and fibrosis in systemic sclerosis. Int. J. Rheumatol. 2011:721608. doi: 10.1155/2011/721608

Campbell, I. L., Erta, M., Lim, S. L., Frausto, R., May, U., Rose-John, S., et al. (2014). Trans-signaling is a dominant mechanism for the pathogenic actions of interleukin-6 in the brain. J. Neurosci. 34, 2503-2513. doi: 10.1523/JNEUROSCI.2830-13.2014

Chen, H., Zhang, X., Liao, N., and Wen, F. (2016). Increased levels of IL-6, sIL$6 \mathrm{R}$, and sgp130 in the aqueous humor and serum of patients with diabetic retinopathy. Mol. Vis. 22, 1005-1014.

Cheung, N., Mitchell, P., and Wong, T. Y. (2010). Diabetic retinopathy. Lancet. 376, 124-136. doi: 10.1016/S0140-6736(09)62124-3

Cunha-Vaz, J., Bernardes, R., and Lobo, C. (2011). Blood-retinal barrier. Eur. J. Ophthalmol. 21(Suppl. 6), S3-S9. doi: 10.5301/EJO.2010.6049

Do, D. V., Wang, X., Vedula, S. S., Marrone, M., Sleilati, G., Hawkins, B. S., et al. (2015). Blood pressure control for diabetic retinopathy. Cochrane Database Syst. Rev. 1:CD006127. doi: 10.1002/14651858.CD006127.pub2

Drucker, C., Gewiese, J., Malchow, S., Scheller, J., and Rose-John, S. (2010). Impact of interleukin-6 classic-and trans-signaling on liver damage and regeneration. J. Autoimmun. 34, 29-37. doi: 10.1016/j.jaut.2009.08.003 endothelial cells, and blockade of this pathway maintained normal endothelial barrier function. Selective inhibition of IL-6 trans-signaling with sgp130Fc also suppressed ocular inflammation and oxidative stress in a mouse model of DR. These findings indicate that a pathway primarily driven by IL$6+$ soluble IL-6R contributes to vascular inflammation in the diabetic retina. Therefore, inhibiting only the trans-signaling pathway of IL-6 will likely be therapeutically superior to a complete IL-6 blockade, because important physiologic functions of IL-6 classical signaling will remain intact. An emerging challenge is identifying means of targeting this inflammatory pathway, as well as determining which DR patients may benefit most from therapies blocking IL-6 trans-signaling. The selective inhibition of IL-6 trans-signaling using the sgp130Fc fusion protein is in clinical trials for the treatment of several inflammatory diseases (Rose-John, 2017) and may be repurposed in the future as an excellent target for DR therapy.

\section{AUTHOR CONTRIBUTIONS}

The author confirms being the sole contributor of this work and has approved it for publication.

\section{FUNDING}

This study was supported by the National Institutes of Health, National Eye Institute (Bethesda, MD, USA) grant \# R01EY026936 awarded to SS.

Ebihara, N., Matsuda, A., Nakamura, S., Matsuda, H., and Murakami, A. (2011). Role of the IL-6 classic- and trans-signaling pathways in corneal sterile inflammation and wound healing. Invest. Ophthalmol. Vis. Sci. 52, 8549-8557. doi: 10.1167/iovs.11-7956

Eshaq, R. S., Aldalati, A. M. Z., Alexander, J. S., and Harris, N. R. (2017). Diabetic retinopathy: breaking the barrier. Pathophysiology. 24, 229-241. doi: 10.1016/j.pathophys.2017.07.001

Fischer, M., Goldschmitt, J., Peschel, C., Brakenhoff, J. P., Kallen, K.-J., Wollmer, A., et al. (1997). A bioactive designer cytokine for human hematopoietic progenitor cell expansion. Nat. Biotechnol. 15, 142-145. doi: $10.1038 /$ nbt0297-142

Fisher, D. T., Chen, Q., Skitzki, J. J., Muhitch, J. B., Zhou, L., Appenheimer, M. M., et al. (2011). IL-6 trans-signaling licenses mouse and human tumor microvascular gateways for trafficking of cytotoxic T cells. J. Clin. Invest. 121, 3846-3859. doi: 10.1172/JCI44952

Fong, D. S., Aiello, L., Gardner, T. W., King, G. L., Blankenship, G., Cavallerano, J. D., et al. (2004). Retinopathy in diabetes. Diabetes Care. 27(Suppl. 1), s84-s87. doi: $10.2337 /$ diacare.27.10.2540

Frey, T., and Antonetti, D. A. (2011). Alterations to the blood-retinal barrier in diabetes: cytokines and reactive oxygen species. Antioxid. Redox Signal. 15, 1271-1284. doi: 10.1089/ars.2011.3906

Fullerton, B., Jeitler, K., Seitz, M., Horvath, K., Berghold, A., and Siebenhofer, A. (2014). Intensive glucose control versus conventional glucose control for type 1 diabetes mellitus. Cochrane Database Syst. Rev. 2014:CD009122. doi: 10.1002/14651858.CD009122.pub2

Funatsu, H., Yamashita, H., Noma, H., Mimura, T., Nakamura, S., Sakata, K., et al. (2005). Aqueous humor levels of cytokines are related to vitreous levels and progression of diabetic retinopathy in diabetic patients. Graefe's Arch. Clin. Exp. Ophthalmol. 243, 3-8. doi: 10.1007/s00417-0040950-7

Gardner, T. W., Larsen, M., Girach, A., Zhi, X., and Protein Kinase C Diabetic Retinopathy Study (PKC-DRS2) Study Group (2009). Diabetic macular 
oedema and visual loss: relationship to location, severity and duration. Acta Ophthalmol. 87, 709-713. doi: 10.1111/j.1755-3768.2009.01545.x

Gardner, T. W., and Sundstrom, J. M. (2017). A proposal for early and personalized treatment of diabetic retinopathy based on clinical pathophysiology and molecular phenotyping. Vis. Res. 139, 153-160. doi: 10.1016/j.visres.2017.03.006

Group, D. P. S., and Chaturvedi, N. (2002). The Diabetic Retinopathy Candesartan Trials (DIRECT) programme, rationale and study design. J. Renin Angiotensin Aldosterone Syst. 3, 255-261. doi: 10.3317/jraas.2002.047

Gustavsson, C., Agardh, C. D., and Agardh, E. (2013). Profile of intraocular tumour necrosis factor-alpha and interleukin-6 in diabetic subjects with different degrees of diabetic retinopathy. Acta Ophthalmol. 91, 445-452. doi: 10.1111/j.1755-3768.2012.02430.x

Hendrick, A. M., Gibson, M. V., and Kulshreshtha, A. (2015). Diabetic retinopathy. Prim. Care. 42, 451-464. doi: 10.1016/j.pop.2015.05.005

Hou, T., Tieu, B. C., Ray, S., Recinos, A. III., Cui, R., Tilton, R. G., et al. (2008). Roles of IL-6-gp130 signaling in vascular inflammation. Curr. Cardiol. Rev. 4:179. doi: 10.2174/157340308785160570

Jo, D. H., Yun, J. H., Cho, C. S., Kim, J. H., Kim, J. H., and Cho, C. H. (2019). Interaction between microglia and retinal pigment epithelial cells determines the integrity of outer blood-retinal barrier in diabetic retinopathy. Glia. 67, 321-331. doi: 10.1002/glia.23542

Jostock, T., Mullberg, J., Ozbek, S., Atreya, R., Blinn, G., Voltz, N., et al. (2001). Soluble gp130 is the natural inhibitor of soluble interleukin6 receptor transsignaling responses. Eur. J. Biochem. 268, 160-167. doi: 10.1046/j.1432-1327.2001.01867.x

Joussen, A. M., Smyth, N., and Niessen, C. (2007). "Pathophysiology of diabetic macular edema," in Diabetic Retinopathy (Karger Publishers), 1-12. doi: 10.1159/000098495

Kawashima, M., Shoji, J., Nakajima, M., Kamura, Y., and Sato, Y. (2007). Soluble IL-6 receptor in vitreous fluid of patients with proliferative diabetic retinopathy. Jpn. J. Ophthalmol. 51, 100-104. doi: 10.1007/s10384-006-0411-4

Kawashiri, S.-,y., Kawakami, A., Yamasaki, S., Imazato, T., Iwamoto, N., Fujikawa, K., et al. (2011). Effects of the anti-interleukin- 6 receptor antibody, tocilizumab, on serum lipid levels in patients with rheumatoid arthritis. Rheumatol. Int. 31, 451-456. doi: 10.1007/s00296-009-1303-y

Kita, T., Clermont, A. C., Murugesan, N., Zhou, Q., Fujisawa, K., Ishibashi, T., et al. (2015). Plasma kallikrein-kinin system as a VEGF-independent mediator of diabetic macular edema. Diabetes. 64, 3588-3599. doi: 10.2337/db15-0317

Klaassen, I., Van Noorden, C. J., and Schlingemann, R. O. (2013). Molecular basis of the inner blood-retinal barrier and its breakdown in diabetic macular edema and other pathological conditions. Prog. Retin. Eye Res. 34, 19-48. doi: 10.1016/j.preteyeres.2013.02.001

Koleva-Georgieva, D. N., Sivkova, N. P., and Terzieva, D. (2011). Serum inflammatory cytokines IL-1 $\beta$, IL- 6 , TNF- $\alpha$ and VEGF have influence on the development of diabetic retinopathy. Folia Med. 53, 44-50. doi: 10.2478/v10153-010-0036-8

Koskela, U. E., Kuusisto, S. M., Nissinen, A. E., Savolainen, M. J., and Liinamaa, M. J. (2013). High vitreous concentration of IL-6 and IL-8, but not of adhesion molecules in relation to plasma concentrations in proliferative diabetic retinopathy. Ophthal. Res. 49, 108-114. doi: 10.1159/000342977

Kraakman, M. J., Kammoun, H. L., Allen, T. L., Deswaerte, V., Henstridge, D. C., Estevez, E., et al. (2015). Blocking IL-6 trans-signaling prevents high-fat diet-induced adipose tissue macrophage recruitment but does not improve insulin resistance. Cell Metab. 21, 403-416. doi: 10.1016/j.cmet.2015. 02.006

Lavine, J. A., Farnoodian, M., Wang, S., Darjatmoko, S. R., Wright, L. S., Gamm, D. M., et al. (2017). $\beta 2$-adrenergic receptor antagonism attenuates CNV through inhibition of VEGF and IL-6 expression. Investig. Ophthalmol. Visual Sci. 58, 299-308. doi: 10.1167/iovs.16-20204

Lee, R., Wong, T. Y., and Sabanayagam, C. (2015). Epidemiology of diabetic retinopathy, diabetic macular edema and related vision loss. Eye Vis. 2:17. doi: 10.1186/s40662-015-0026-2

Lin, Y.-M., Chang, Z.-L., Liao, Y.-Y., Chou, M.-C., and Tang, C.-H. (2013). IL-6 promotes ICAM-1 expression and cell motility in human osteosarcoma. Cancer Lett. 328, 135-143. doi: 10.1016/j.canlet.2012.08.029

Mesquida, M., Drawnel, F., Lait, P. J., Copland, D. A., Stimpson, M. L., Llorenc, V., et al. (2019). Modelling macular edema: the effect of IL-6 and IL-6R blockade on human blood-retinal barrier integrity in vitro. Transl. Vis. Sci. Technol. 8:32. doi: $10.1167 /$ tvst.8.5.32

Mocan, M. C., Kadayifcilar, S., and Eldem, B. (2006). Elevated intravitreal interleukin-6 levels in patients with proliferative diabetic retinopathy. Can. J. Ophthalmol. 41, 747-752. doi: 10.3129/106-070

Noda, K., Nakao, S., Ishida, S., and Ishibashi, T. (2012). Leukocyte adhesion molecules in diabetic retinopathy. J. Ophthalmol. 2012:279037. doi: 10.1155/2012/279037

Ohsugi, Y., and Kishimoto, T. (2008). The recombinant humanized anti-IL-6 receptor antibody tocilizumab, an innovative drug for the treatment of rheumatoid arthritis. Expert Opin. Biol. Ther. 8, 669-681. doi: 10.1517/14712598.8.5.669

Rabe, B., Chalaris, A., May, U., Waetzig, G. H., Seegert, D., Williams, A. S., et al. (2008). Transgenic blockade of interleukin 6 transsignaling abrogates inflammation. Blood. 111, 1021-1028. doi: 10.1182/blood-2007-07-102137

Reeh, H., Rudolph, N., Billing, U., Christen, H., Streif, S., Bullinger, E., et al. (2019). Response to IL-6 trans-and IL-6 classic signalling is determined by the ratio of the IL- 6 receptor $\alpha$ to gp130 expression: fusing experimental insights and dynamic modelling. Cell Commun. Signal. 17, 1-21. doi: 10.1186/s12964-019-0356-0

Robinson, R., Srinivasan, M., Shanmugam, A., Ward, A., Ganapathy, V., Bloom, J., et al. (2020). Interleukin-6 trans-signaling inhibition prevents oxidative stress in a mouse model of early diabetic retinopathy. Redox Biol. 34:101574. doi: 10.1016/j.redox.2020.101574

Rojas, M., Zhang, W., Lee, D. L., Romero, M. J., Nguyen, D. T., AlShabrawey, M., et al. (2010). Role of IL-6 in angiotensin II-induced retinal vascular inflammation. Investig. Ophthalmol. Vis. Sci. 51, 1709-1718. doi: 10.1167/iovs.09-3375

Romano, M., Sironi, M., Toniatti, C., Polentarutti, N., Fruscella, P., Ghezzi, P., et al. (1997). Role of IL-6 and its soluble receptor in induction of chemokines and leukocyte recruitment. Immunity. 6, 315-325. doi: 10.1016/S1074-7613(00)80334-9

Rose-John, S. (2012). IL-6 trans-signaling via the soluble IL-6 receptor: importance for the pro-inflammatory activities of IL-6. Int. J. Biol. Sci. 8:1237. doi: $10.7150 /$ ijbs.4989

Rose-John, S. (2017). The soluble interleukin 6 receptor: advanced therapeutic options in inflammation. Clin. Pharmacol. Ther. 102, 591-598. doi: 10.1002/cpt.782

Roy, S., Kern, T. S., Song, B., and Stuebe, C. (2017). Mechanistic insights into pathological changes in the diabetic retina: implications for targeting diabetic retinopathy. Am. J. Pathol. 187, 9-19. doi: 10.1016/j.ajpath.2016.08.022

Scheller, J., Chalaris, A., Schmidt-Arras, D., and Rose-John, S. (2011). The pro- and anti-inflammatory properties of the cytokine interleukin-6. Biochim. Biophys. Acta. 1813, 878-888. doi: 10.1016/j.bbamcr.2011.01.034

Sharma, S., Purohit, S., Sharma, A., Hopkins, D., Steed, L., Bode, B., et al. (2015). Elevated serum levels of soluble TNF receptors and adhesion molecules are associated with diabetic retinopathy in patients with type-1 diabetes. Mediat. Inflamm. 2015:279393. doi: 10.1155/2015/279393

Shimizu, E., Funatsu, H., Yamashita, H., Yamashita, T., and Hori, S. (2002). Plasma level of interleukin- 6 is an indicator for predicting diabetic macular edema. Jpn. J. Ophthalmol. 46, 78-83. doi: 10.1016/S0021-5155(01)00452-X

Srividya, G., Jain, M., Mahalakshmi, K., Gayathri, S., Raman, R., and Angayarkanni, N. (2018). A novel and less invasive technique to assess cytokine profile of vitreous in patients of diabetic macular oedema. Eye. 32, 820-829. doi: 10.1038/eye.2017.285

Stuhlmann-Laeisz, C., Lang, S., Chalaris, A., Krzysztof, P., Enge, S., Eichler, J., et al. (2006). Forced dimerization of gp130 leads to constitutive STAT3 activation, cytokine-independent growth, and blockade of differentiation of embryonic stem cells. Mol. Biol. Cell. 17, 2986-2995. doi: 10.1091/mbc.e05-12-1129

Sugimoto, M., Cutler, A., Shen, B., Moss, S. E., Iyengar, S. K., Klein, R., et al. (2013). Inhibition of EGF signaling protects the diabetic retina from insulin-induced vascular leakage. Am. J. Pathol. 183, 987-995. doi: 10.1016/j.ajpath.2013.05.017

Tang, J., and Kern, T. S. (2011). Inflammation in diabetic retinopathy. Prog. Retin. Eye Res. 30, 343-358. doi: 10.1016/j.preteyeres.2011.05.002

Tenhumberg, S., Waetzig, G. H., Chalaris, A., Rabe, B., Seegert, D., Scheller, J., et al. (2008). Structure-guided optimization of the interleukin-6 trans-signaling antagonist sgp130. J. Biol. Chem. 283, 27200-27207. doi: 10.1074/jbc.M803694200 
Valle, M. L., Dworshak, J., Sharma, A., Ibrahim, A. S., Al-Shabrawey, M., and Sharma, S. (2019). Inhibition of interleukin-6 trans-signaling prevents inflammation and endothelial barrier disruption in retinal endothelial cells. Exp. Eye Res. 178, 27-36. doi: 10.1016/j.exer.2018.09.009

Wei, L. H., Chou, C. H., Chen, M. W., Rose-John, S., Kuo, M. L., Chen, S. U., et al. (2013). The role of IL-6 trans-signaling in vascular leakage: implications for ovarian hyperstimulation syndrome in a murine model. J. Clin. Endocrinol. Metab. 98, E472-E484. doi: 10.1210/jc.2012-3462

Wolf, J., Waetzig, G. H., Chalaris, A., Reinheimer, T. M., Wege, H., Rose-John, S., et al. (2016). Different soluble forms of the interleukin-6 family signal transducer gp130 fine-tune the blockade of interleukin-6 trans-signaling. J. Biol. Chem. 291, 16186-16196. doi: 10.1074/jbc.M116.718551

Wung, B., Ni, C., and Wang, D. (2005). ICAM-1 induction by TNF $\alpha$ and IL-6 is mediated by distinct pathways via Rac in endothelial cells. J. Biomed. Sci. 12, 91-101. doi: 10.1007/s11373-004-8170-Z

Yun, J. H., Park, S. W., Kim, K. J., Bae, J. S., Lee, E. H., Paek, S. H., et al. (2017). Endothelial STAT3 activation increases vascular leakage through downregulating tight junction proteins: implications for diabetic retinopathy J. Cell. Physiol. 232, 1123-1134. doi: 10.1002/jcp.25575

Zhang, X., Saaddine, J. B., Chou, C. F., Cotch, M. F., Cheng, Y. J., Geiss, L. S., et al. (2010). Prevalence of diabetic retinopathy in the United States, 2005-2008. JAMA. 304, 649-656. doi: 10.1001/jama.201 0.1111

Conflict of Interest: The author declares that the research was conducted in the absence of any commercial or financial relationships that could be construed as a potential conflict of interest.

Copyright (c) 2021 Sharma. This is an open-access article distributed under the terms of the Creative Commons Attribution License (CC BY). The use, distribution or reproduction in other forums is permitted, provided the original author(s) and the copyright owner(s) are credited and that the original publication in this journal is cited, in accordance with accepted academic practice. No use, distribution or reproduction is permitted which does not comply with these terms. 